\title{
High temperature gas effect on the Prandtl-Meyer function with application for supersonic nozzle design
}

\author{
Mohamed Boun-Jad ${ }^{1,3}$, Toufik Zebbiche ${ }^{2, a}$ And Abderrazak Allali ${ }^{3}$ \\ 1 Department of Mechanical Engineering, Faculty of Technology, University of Blida 1, BP 270, 09000 Blida, Algeria \\ 2 Institute of Aeronautics and Space Studies, University of Blida 1, BP 270, 09000 Blida, Algeria \\ 3 Aircraft Laboratory, Institute of Aeronautics and Space Studies, University of Blida 1, BP 270, 09000 Blida, Algeria
}

Received 24 December 2015, Accepted 30 April 2016

\begin{abstract}
This work is to develop a new computational program to determine the effect of using gas propellant of the combustion chamber at high temperature on the calculation of the value of the Prandtl Meyer function and application to supersonic nozzles design. The selected gases are the $\mathrm{H}_{2}, \mathrm{O}_{2}, \mathrm{~N}_{2}, \mathrm{CO}$, $\mathrm{CO}_{2}, \mathrm{H}_{2} \mathrm{O}, \mathrm{NH}_{3}, \mathrm{CH}_{4}$ and air. Prandtl Meyer function depends on the stagnation temperature, Mach number and the gas used. The specific heat at constant pressure and the enthalpy of the gases vary with the temperature and the selected gas. The gas is still considered as perfect and it will be calorically imperfect and thermally perfect below the threshold of dissociation of molecules. A calculation of the difference between the Prandtl Meyer function for different gases with the air is made for the purpose of comparison. The application is made for designing the supersonic $M L N$ nozzle at high temperature.
\end{abstract}

Key words: Supersonic flow / supersonic nozzle / design / high temperature / Prandtl Meyer function / calorically imperfect gas / numerical integration / specific heat at constant pressure / gas / error

\section{Introduction}

Gases play an important role in the propulsion of aerospace vehicles. They influence the behavior of the supersonic flows and in particular on all design parameters $[1,2]$. For supersonic nozzles of rockets, missiles and supersonic aircraft engines, it is desirable to have small masses of the craft and high possible thrust. For supersonic blowers, it is desired to have nozzles with low temperature distribution and a large possible of exit section to place the prototype and the tools and measuring devices without damage $[1,2]$.

In the design of aerospace propulsion several types of supersonic nozzle are encountered, each with practical value, performance and favored scope. Examples bell shaped nozzle, $M L N$ nozzle, plug nozzle, expansion deflexion nozzle, annular nozzle, dual bell nozzle, Laval nozzle, etc. [2-8]. Each constructor uses a specific form according to the performance delivered by the nozzle [2-8] which falls in accordance with the need for construction. We are interested in the present work to make an application to the $M L N$ nozzle to see its potential advantage in what has minimum length and weight and high possible thrust from the majority of the indicated nozzles [2-8].

We have to obtain the performances indicated previously (small weight, large $C_{F}$ ), using a propellant gas

\footnotetext{
a Corresponding author: z_toufik270169@yahoo.fr
}

that meets these requirements. Usually these properties are found for the propulsion of gas called cold gas $[9,10]$. Air meets the need for more reason because it exists in quantities in nature.

References [5,11-17] have studied at high temperature for air on the supersonic nozzles design by the method of characteristics. This method is based on the $P M$ function. For air at high temperature, it is presented in references $[18,19]$.

At low temperatures, $C_{P}$ and $\gamma$ are assumed to be constant and do not depend on temperature. Studies on the design of supersonic nozzles and the $P M$ function are shown in references $[1,2]$.

The aim of this work is to develop a new computational program to study the effect of using gas of propulsion rest on at high temperature on the PM function and to make application for designing the supersonic $M L N$ nozzle. The molecules of the selected gases have one or two kinds of atoms which are $\mathrm{H}_{2}, \mathrm{O}_{2}, \mathrm{~N}_{2}, \mathrm{CO}, \mathrm{CO}_{2}, \mathrm{H}_{2} \mathrm{O}$, $\mathrm{NH}_{3}, \mathrm{CH}_{4}$ and air. For substances still the gas temperature must be in a specific range for not having a dissociation of the molecules. This interval varies from one gas to another [20-27], usually between $200 \mathrm{~K}$ and $6000 \mathrm{~K}$ [2027 ] except for air under $3550 \mathrm{~K}[1,2]$. The gas is considered as perfect, including the equation of state $(P=\rho R T)$ still valid. It is considered calloricaly imperfect seen the change in the function $C_{P}(T)$ varying with temperature. 


\section{Nomenclature}

\begin{tabular}{|ll|}
\hline$M$ & Mach number \\
$V$ & Velocity \\
$\mu$ & Mach angle \\
$x$ & Abscissa of the a section in the nozzle \\
$y$ & Radius of the nozzle section \\
$T$ & Temperature \\
$\rho$ & Density \\
$A$ & Section area of the nozzle \\
$R$ & Thermodynamic constant of gas \\
$H$ & Enthalpy \\
$C_{P}$ & Specific heat at constant pressure \\
$\gamma$ & Specific heat ratio \\
$\theta$ & Deviation of the flow at the throat of the nozzle \\
$\nu$ & Prandtl Meyer function \\
$\varepsilon$ & Error \\
$a^{\prime}, b^{\prime}, c^{\prime}$ & Coefficients of $C_{P}(T)$ in Equation $(1)$ \\
$C_{F}$ & Pressure force coefficient for the nozzle \\
$C_{M a s s}$ & Mass of the nozzle in adimensional value \\
$L$ & Length of the nozzle \\
$P M$ & Prandtl Meyer \\
$M L N$ & Minimum Length Nozzle \\
$H T$ & High Temperature \\
$P G$ & Perfect Gas \\
\hline & \\
\hline 0 & Stagnation state (combustion chamber) \\
$*$ & Critical condition \\
$S$ & Supersonic state \\
$E$ & Exit section \\
\hline
\end{tabular}

It is considered again thermally perfect because the temperature of the dissociation of molecules is not reached. For the chosen gas in a variation according to the relation (1) of $C_{P}(T)$ by references [20-27] is found.

$$
C_{P}(T)=a^{\prime}+b^{\prime} T+\frac{c^{\prime}}{T^{2}}
$$

Nine gases are selected, indicated by Table 1, They are selected from the group of gases found in the literature [20-27]. We focus on the specific heat $C_{P}(T)$ at high temperature and $R$ gas constant [20-27]. The coefficients of the function (1) for the selected gas are shown in Table 1.

Concerning the air, the variation of $C_{P}(T)$ is chosen as a polynomial of 9 th degree $[4,5,11-19]$.

The values of $C_{P}$ and $\gamma$ at low temperature under an ideal gas, and for calorically and thermally perfect gas for 9 selected gases and the constant $R$ are shown in Table 2 [20-27].

\section{Mathematical formulation}

The deviation of a supersonic flow can cause expansion or compression. When the intensity of the shock $\Delta P / P$ approaches zero, provide the necessary tool for the study
Table 1. Coefficients of $C_{P}(T)$ function for selected gases.

\begin{tabular}{ccccc}
\hline$N$ & Gas & $a^{\prime}$ & $b^{\prime}$ & $c^{\prime}$ \\
& & $\mathrm{J}^{\prime} \mathrm{K}^{-1} . \mathrm{mol}^{-1}$ & $\mathrm{~J} . K^{-2} . \mathrm{mol}^{-1}$ & $\mathrm{~J} . \mathrm{K} . \mathrm{mol}^{-1}$ \\
\hline 1 & $\mathrm{H}_{2}$ & 27.28 & 3.26 & 0.50 \\
2 & $\mathrm{O}_{2}$ & 29.96 & 4.18 & -1.67 \\
3 & $\mathrm{~N}_{2}$ & 28.58 & 3.76 & -0.50 \\
4 & $\mathrm{CO}$ & 28.41 & 4.10 & -0.46 \\
5 & $\mathrm{CO}_{2}$ & 44.22 & 8.79 & -8.62 \\
6 & $\mathrm{H}_{2} \mathrm{O}$ & 30.54 & 10.29 & 0.08 \\
7 & $\mathrm{NH}_{3}$ & 29.75 & 25.10 & -1.55 \\
8 & $\mathrm{CH}_{4}$ & 23.64 & 47.86 & -1.92 \\
9 & $\mathrm{Air}$ & Polynomial of 9th degree $[4,5,11-19]$ \\
\hline
\end{tabular}

of this phenomenon is provided [28,29]. Normal speed to the wave is the speed of sound. A small flow deviation $\Delta \theta$ downstream of the wave is linked to a speed difference $\Delta V$ by the following relationship $[28,29]$ :

$$
\mathrm{d} \theta=-\frac{\cot g(\mu)}{V} \mathrm{~d} V .
$$

By inserting the relationship between the Mach angle $\mu$ and the Mach number $M$ in Equation (2) yields:

$$
\mathrm{d} \theta=\mathrm{d} \nu=\left(M^{2}-1\right)^{1 / 2} \frac{\mathrm{d} V}{V}
$$

The relationship (3) is very important for to the study of the supersonic isentropic flow external or internal. Note that the angle $\mathrm{d} \theta$ is counted positive when the flow is away from the direction normal to the wave (compression wave) and negative when the flow approaches the direction normal to the wave (expansion wave).

The energy conservation equation in differential form $[3,4,11-17,28]$ is written:

$$
C_{P} \mathrm{~d} T+V \mathrm{~d} V=0
$$

Which can be written after doing mathematical transformations:

$$
\frac{\mathrm{d} V}{V}=-\frac{C_{P}(T)}{2 H(T)} \mathrm{d} T
$$

For the integration of Equation (3), it should be expressed $\mathrm{d} V / V$ by the expression $(5)[18,19]$. After integration between the sonic state $\left(T=T_{*}, M=1.00\right)$ and the supersonic state $\left(T<T_{*}, M>1.00\right)$ we obtain:

$$
\nu(T)=\int_{T}^{T_{*}} \frac{C_{P}(T)}{2 H(T)} \sqrt{M^{2}(T)-1} \mathrm{~d} T
$$

The values of $M$ and $T$ are connected by [3,4,11-19].

$$
M(T)=\sqrt{\frac{2 H(T)}{\gamma(T) R T}}
$$

With

$$
\begin{aligned}
\gamma(T) & =\frac{C_{P}(T)}{C_{P}(T)-R} \\
H(T) & =\int_{T}^{T_{0}} C_{P}(T) \mathrm{d} T
\end{aligned}
$$


Table 2. Values of $C P$ and $\gamma$ for perfect gas assumptions and thermodynamics constants $R$ for some selected gases.

\begin{tabular}{cccccc}
\hline$N$ & \multirow{2}{*}{ Gas } & $\begin{array}{c}\text { Molecular } \\
\text { weight }(\mathrm{g})\end{array}$ & $\begin{array}{c}\mathrm{C}_{P} \\
\mathrm{~J} . \mathrm{kg}^{-1} . \mathrm{K}^{-1}\end{array}$ & $\begin{array}{c}\gamma \\
\mathrm{J} . \mathrm{kg}^{-1} . \mathrm{K}^{-1}\end{array}$ & $R$ \\
\hline 1 & $\mathrm{H}_{2}$ & 2.01588 & 14304.594 & 1.4051 & 4124.506 \\
2 & $\mathrm{O}_{2}$ & 31.99880 & 918.1079 & 1.3947 & 259.8381 \\
3 & $\mathrm{~N}_{2}$ & 28.01348 & 1039.6548 & 1.3995 & 296.8038 \\
4 & $\mathrm{CO}$ & 28.01040 & 1040.3705 & 1.3992 & 296.8385 \\
5 & $\mathrm{CO}_{2}$ & 44.00980 & 844.22714 & 1.2883 & 188.9240 \\
6 & $\mathrm{H}_{2} \mathrm{O}$ & 18.01528 & 1864.4012 & 1.3289 & 461.5254 \\
7 & $\mathrm{NH}_{3}$ & 17.03056 & 2092.1466 & 1.3043 & 488.2111 \\
8 & $\mathrm{CH}_{4}$ & 16.04276 & 2224.7529 & 1.3037 & 518.2717 \\
9 & Air & 28.96003 & 1001.2893 & 1.4020 & 287.1029 \\
\hline
\end{tabular}

To demonstrate the relationship (7), we use the definition of Mach number depending on the speed of sound and the flow velocity and to demonstrate the relationship (9) it is used for energy conservation equation in differential form and to make integration between a supersonic state having the temperature $T$ and the stagnation state having the temperature $T_{0}$.

The value of $T_{*}$ and $T_{S}$ corresponding, respectively, to $M=1.00$ and $M=M_{S}$ can each one be obtained by the resolution of Equation (7) by using the bipartition algorithm [30,31]. The two values depend on $T_{0}, R$ and $C_{P}(T)$ of each gas. The value of $\nu_{S}$ can be obtained by integration of the function (2) in the interval $\left[T_{S} ; T_{*}\right]$ by using the Simpson's quadrature [18] or by special Gauss Legendre quadrature [19] for fast calculation.

To make a comparison between the case at high temperature and the case of an ideal gas, we recall the Prandtl-Meyer function given by the theory of an ideal gas $[29,32]$ :

$$
\begin{aligned}
\nu(M)= & \sqrt{\frac{\gamma+1}{\gamma-1}} \operatorname{arctg} \sqrt{\frac{\gamma+1}{\gamma-1}\left(M^{2}-1\right)} \\
& -\operatorname{arctg} \sqrt{M^{2}-1}
\end{aligned}
$$

The $P M$ function (10) is explicitly connected with the Mach number, which is the main variable for the ideal gas, on the contrary to our model High Temperature, where the main variable is the temperature due to the Equation (7) linking $M$ and $T$; we cannot determine an analytical expression of its inverse.

Then the relation (6) obtained is a generalization of the $P M$ function of the case of an ideal gas (10) with constant specific heats. Thus the expression of the $P M$ function of the high temperature gas (Gas calorically imperfect and thermally perfect) is obtained when the variation of the specific heat $C_{P}$ depending on the temperature is held in account. The most $T_{0}$ or $M$ increases, the error between the relations (6) and (10) also increases and becomes significant.

The most application and use of the $P M$ function are in the compatibilities and characteristics equations for designing of supersonic nozzle, like $M L N$ by the method of characteristics. Figure 1 shows the various regions of the flow that can have $M L N$ nozzle to have uniform and parallel flow to the exit section. So the area $O A B$ is appointed by Kernel region. It is of not simple type. The region $A B E$

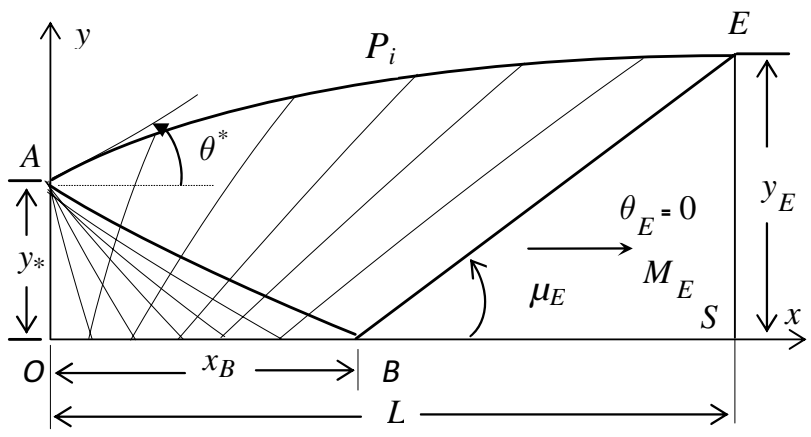

Fig. 1. Presentation of the flow field in the nozzle.

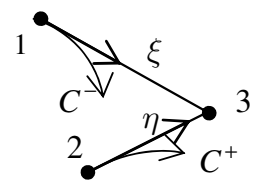

Fig. 2. Illustration Mach lines upward and downward.

is named by transition region. It is a simple region and the $B S E$ region is appointed by uniform region. However, the Mach number is constant at all points in this region. The wall of the nozzle is a priori unknown. It is determined numerically for the desired condition. The search of the wall and the calculation of the internal flow are done by the method of characteristics in the case assumptions at $H T[3,13,14]$.

The calculation is based on the use of the method of characteristics at HT. The equations of compatibilities and characteristics respectively valid on upward and downward characteristic, as presented in Figure 2, are represented by $[3,13,14]$ :

$$
\begin{aligned}
& \left\{\begin{array}{l}
-\frac{C_{P}(T)}{2 H(T)} \sqrt{M^{2}(T)-1} d T+d \theta=0 \\
\frac{d y}{d x}=\operatorname{tg}(\theta-\mu)
\end{array}\right. \\
& \left\{\begin{array}{l}
-\frac{C_{P}(T)}{2 H(T)} \sqrt{M^{2}(T)-1} d T-d \theta=0 \\
\frac{d y}{d x}=\operatorname{tg}(\theta+\mu)
\end{array}\right.
\end{aligned}
$$

The discretization of the system (11) and (12) gives four algebraic equations with four unknowns $(x, y, T$ and $\theta$ ) at each point of the flow field. The resolution was made by the finite difference method with predictor corrector $[3,4,13,17]$. 


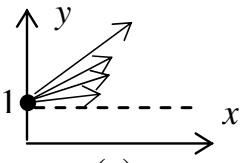

(a)

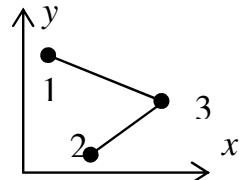

(b)

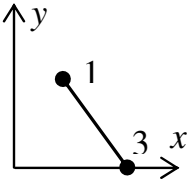

(c)
Fig. 3. Different points of the flow field. (a) Point at the expansion center (Point $A$ in Fig. 1). (b) Internal point. (c) Point on the axis of symmetry.

We can have three types of points in the flow as presented in Figure 3.

The flow parameters in the points 1 and 2 of the Figure 3 are known. The problem is to determine the parameters in the point 3 by solving the system of Equations (11) and (12) simultaneously.

Parameters at a point depend only on the properties at the upstream points. It is a property of a supersonic flow $[3,4,11,13-17,29,32]$.

\section{Comparison with air}

The air is generally used as a propellant gas in most aerospace applications considering its existence in quantity in nature. The studies presented in references [3-11] are made only for air. To see the advantage or disadvantage of such gas with respect to air, we determine the difference between the function $\nu$ of air and other gases by the following relation.

$$
\varepsilon(\%)=\left|1-\frac{\nu_{\mathrm{Gas}}}{\nu_{\mathrm{Air}}}\right| \times 100
$$

\section{Applications}

The case of the flow diversion to the throat of a supersonic nozzle-type $M L N$ giving a uniform and parallel flow at the exit section can be taken as a good example of application. In the $2 \mathrm{D}$ case, the deviation of the nozzle $\theta^{*}$ at the throat is connected to the exit Mach number $M_{E}$ by the following relationship $[3,13,14]$.

$$
\theta^{*}=\frac{\nu\left(M_{E}\right)}{2}
$$

For axisymmetric case, the angle $\theta^{*}$ is determined numerically based on $M_{E}$ [8].

Relation (14) is very advantageous in the field of gas dynamics. It connects the exit Mach number $M_{E}$ of the nozzle with the initial deflection $\theta^{*}$ (by the use of $P M$ function) that must have the nozzle at the nozzle throat. This formula is valid only if the nozzle gives a uniform and parallel flow to the exit section to have, therefore, a complete expansion of the flow through the nozzle, for avoiding the thrust losses caused by the tilting of the nozzle at the exit and for not yet the birth of the shock wave

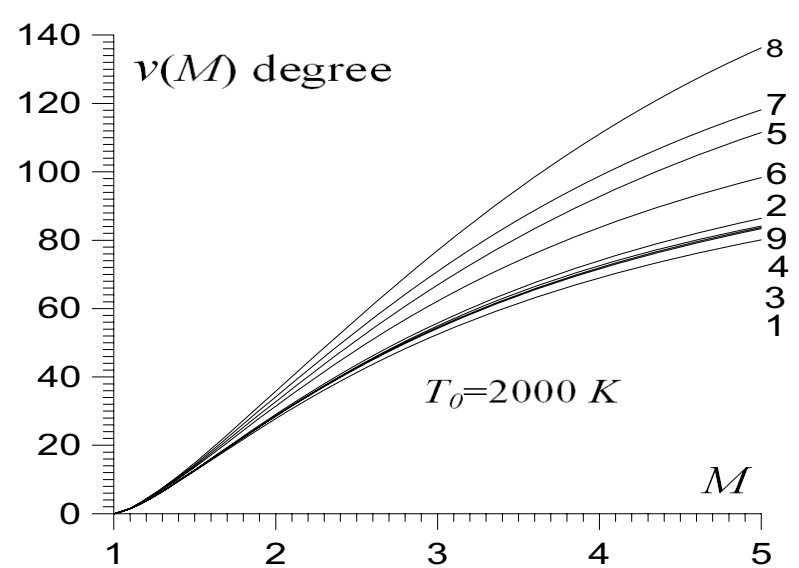

Fig. 4. Gas effect at high temperature on the variation of $\nu$ versus $M$.

in the interior of the nozzle. In such cases if it is the dimensioning of the nozzle giving $M_{E}$ at the exit can be known the inclination of the wall. This inclination is maximum and there will be a recovery of the wall to the exit section, which is not the case for the axisymmetric nozzle, wherein the nozzle has an inflection point. For the formula (14) can be used the compatibility equations in $2 \mathrm{D}$ from conservations equations of gas dynamics by applying the method of characteristics because the flow is supersonic.

We see the influence of the $P M$ function in Equation (14). Then the angle $\theta^{*}$ is half the value of $\nu$ corresponding to the $\nu_{S}$ of the nozzle.

The second application is for external flow. The taken example is the dihedron deviation. If the deviation with respect to the dihedron upstream flow is given by $\theta$ for example, the Mach number $M_{2}$ just after the expansion will be calculated with respect to the upstream Mach number $M_{1}$, by solving the following equation.

$$
\theta=\nu\left(M_{2}\right)-\nu\left(M_{1}\right)
$$

The values of $M_{1}$ and $\theta$ are known and $M_{2}$ is unknown. The problem is the inversion of the $P M$ function to determine the value of $M_{2}$.

\section{Results and comments}

Figures 4, 5 and 10 each contain 9 curves for 9 selected gases as shown in Table 1 . The curve 1 shows the variation for the $\mathrm{H}_{2}$ gas. Curve 2 for $\mathrm{O}_{2}$. Curve 3 for $\mathrm{N}_{2}$. Curve 4 for CO. Curve $5 \mathrm{CO}_{2}$. Curve 6 for $\mathrm{H}_{2} \mathrm{O}$. Curve 7 for $\mathrm{NH}_{3}$. Curve 8 for $\mathrm{CH}_{4}$ and the curve 9 for air.

Table 3 presents some values of gas effect on $\theta^{*}$ according to the Mach number for $T_{0}=2000 \mathrm{~K}$.

Figure 4 shows the effect of propelling gas on the variation of $P M$ according to $M$. The example chosen is for $T_{0}=2000 \mathrm{~K}$.

We note that the most gas has a smaller $\gamma$ ratio, the most value of $\nu$ is large, which is the is case of $\mathrm{CH}_{4}$. The $\mathrm{H}_{2}$ gas gives the smallest value of $\nu$. 
Table 3. Gas effect on $\theta^{*}$ for $T_{0}=2000 \mathrm{~K}$.

\begin{tabular}{cccccc}
\hline$N$ & Gas & $M_{E}=2.00$ & $M_{E}=3.00$ & $M_{E}=4.00$ & $M_{E}=5.00$ \\
\hline 1 & $\mathrm{H}_{2}$ & $13.90 \mathrm{deg}$ & $26.22 \mathrm{deg}$ & $34.47 \mathrm{deg}$ & $40.06 \mathrm{deg}$ \\
2 & $\mathrm{O}_{2}$ & $14.52 \mathrm{deg}$ & $27.88 \mathrm{deg}$ & $37.01 \mathrm{deg}$ & $43.21 \mathrm{deg}$ \\
3 & $\mathrm{~N}_{2}$ & $14.23 \mathrm{deg}$ & $27.10 \mathrm{deg}$ & $35.79 \mathrm{deg}$ & $41.68 \mathrm{deg}$ \\
4 & $\mathrm{CO}$ & $14.30 \mathrm{deg}$ & $27.23 \mathrm{deg}$ & $35.96 \mathrm{deg}$ & $41.87 \mathrm{deg}$ \\
5 & $\mathrm{CO}_{2}$ & $16.38 \mathrm{deg}$ & $33.44 \mathrm{deg}$ & $46.38 \mathrm{deg}$ & $55.74 \mathrm{deg}$ \\
6 & $\mathrm{H}_{2} \mathrm{O}$ & $15.71 \mathrm{deg}$ & $31.07 \mathrm{deg}$ & $41.85 \mathrm{deg}$ & $49.16 \mathrm{deg}$ \\
7 & $\mathrm{NH}_{3}$ & $17.07 \mathrm{deg}$ & $35.44 \mathrm{deg}$ & $49.38 \mathrm{deg}$ & $59.08 \mathrm{deg}$ \\
8 & $\mathrm{CH}_{4}$ & $17.90 \mathrm{deg}$ & $38.50 \mathrm{deg}$ & $55.52 \mathrm{deg}$ & $68.15 \mathrm{deg}$ \\
9 & $\mathrm{Air}$ & $14.31 \mathrm{deg}$ & $27.46 \mathrm{deg}$ & $36.26 \mathrm{deg}$ & $42.06 \mathrm{deg}$ \\
\hline
\end{tabular}

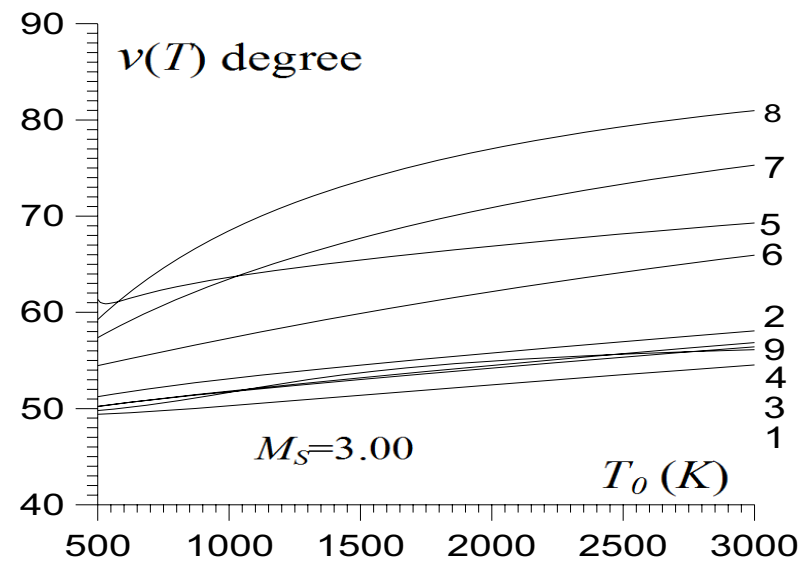

Fig. 5. Gas effect at high temperature on the variation of $\nu$ versus $T_{0}$.

The results for the air shown in curve 9, can be found in references $[3,13,14]$. They are presented for purposes of comparison with other gases.

Figure 5 shows the variation of $\nu$ as function of $T_{0}$ for the different gases when $M_{S}=3.00$. This figure illustrates the effect of gas and $T_{0}$ on the value of $\nu$. The most $T_{0}$ increases, the most $\nu$ is high. Then the most $T_{0}$ and $M_{S}$ are large and $\gamma$ is small (gas effect), the most the length, weight and thrust coefficient of the nozzle will be high.

In Figures 6-8 are shown the variation of the function $\nu$ and the imperfection respectively for all selected gases $\left(\mathrm{H}_{2}, \mathrm{O}_{2}, \mathrm{~N}_{2}, \mathrm{CO}, \mathrm{CO}_{2}, \mathrm{H}_{2} \mathrm{O}, \mathrm{NH}_{3}, \mathrm{CH}_{4}\right.$ and air) as a function of $M$ at high temperature for $T_{0}=1000 \mathrm{~K}$, $2000 \mathrm{~K}$ and $3000 \mathrm{~K}$ and for the case of perfect gas (low temperature $298.15 \mathrm{~K}$, curve 4 ). It is noted a difference between the values found but the rate of change is the same for the different gases. For example, when $T_{0}=2000 \mathrm{~K}$ and $M_{S}=5.00, \nu_{\mathrm{CH} 4}=136.31$ degree and $\nu_{\mathrm{H} 2}=80.12$ degree.

About imperfection, we notice that it is always greater than unity. This shows that the results of the $P M$ function for high temperature case are always greater than those of the ideal gas model case at low temperature. Then the most $T_{0}$ is longer, the imperfection will be high, which further shows the influence of the temperature $T_{0}$ on the $P M$ function. The imperfection can reach 1.72 for $\mathrm{CH}_{4}$ when $T_{0}=3000 \mathrm{~K}$, that is to say that the gap may reach $72 \%$ between the results of the two models. The maximum rate
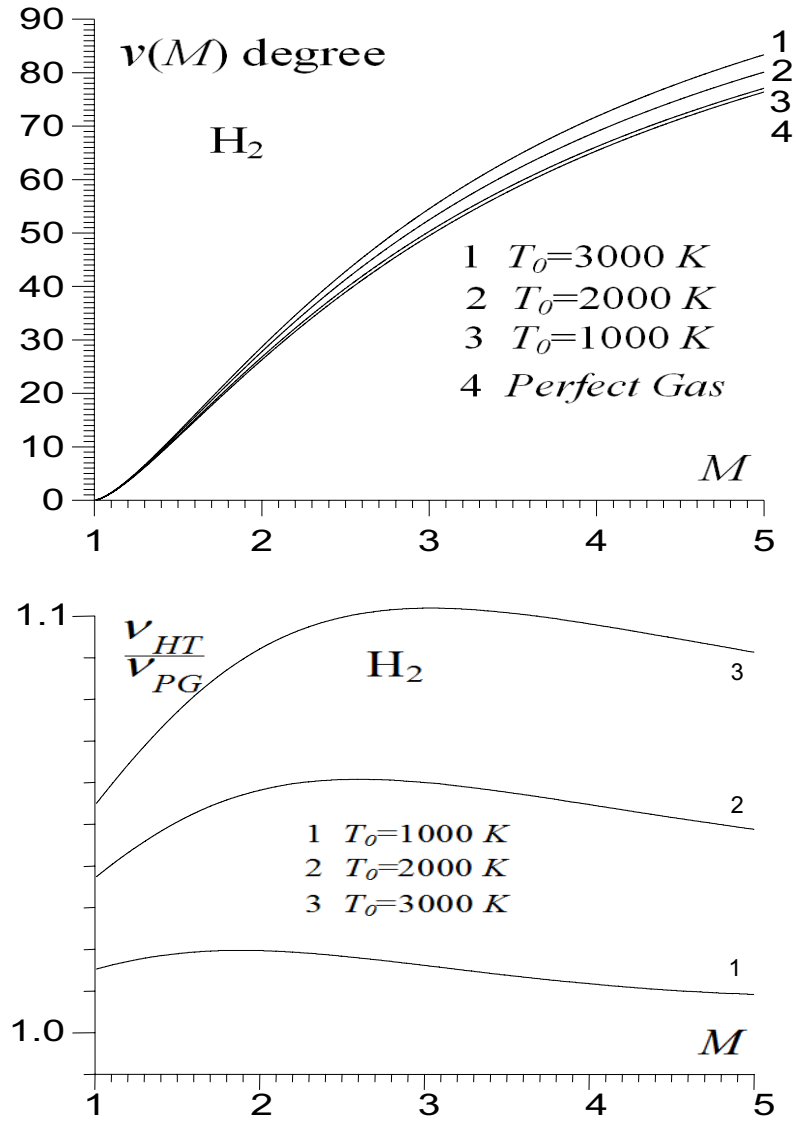

Fig. 6. Effect of caloric imperfections on the Prandtl Meyer function for $\mathrm{H}_{2}$ gas.

of imperfection, to $\mathrm{H}_{2}, \mathrm{O}_{2}, \mathrm{~N}_{2}, \mathrm{CO}, \mathrm{CO}_{2}, \mathrm{H}_{2} \mathrm{O}, \mathrm{NH}_{3}, \mathrm{CH}_{4}$ and air can reach respectively to $10.19 \%, 16.84 \%, 13.56 \%$, $14.44 \%, 28.88 \%, 24.87 \%, 48.35 \%, 71.16 \%$ and $14.24 \%$ for $T_{0}=3000 \mathrm{~K}$. The most $T_{0}$ increases, the most the rate of defect also increases. Higher the rate of imperfection, the most the gas concerned is not convenient for use at this temperature as a propellant gas for aerospace vehicles. This is the case, for example, for $\mathrm{CH}_{4}, \mathrm{NH}_{3}, \mathrm{H}_{2} \mathrm{O}$ and $\mathrm{CO}_{2}$. As a possible solution for these gases, use a stagnation temperature $T_{0}$ the smallest possible for aerospace propulsion, but not recommended. While for $\mathrm{H}_{2}, \mathrm{O}_{2}, \mathrm{~N}_{2}$ and air, and since the rate of imperfection is small, we can use a high value of $T_{0}$ if necessary. 

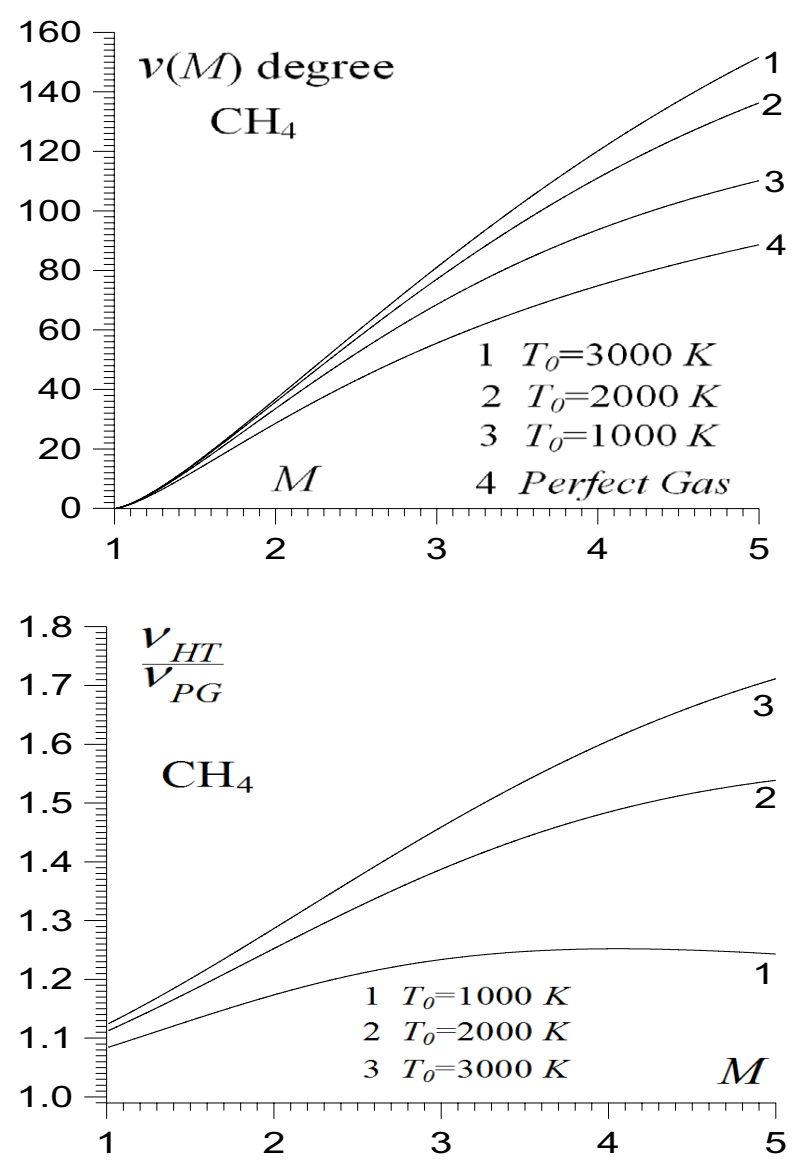

Fig. 7. Effect of caloric imperfections on the Prandtl Meyer function for $\mathrm{CH}_{4}$ gas.

Yet the supersonic Mach number affects the rate of imperfection.

By comparing the results in Figure 8 obtained for the air by our numerical program with results on $P M$ function presented in $[18,19]$, we note that there is a maximum relative error that does not exceed $2.47 \%$

On Table 4, the effect of gas on the Mach number is shown when the function $\nu$ is given for $T_{0}=2000 \mathrm{~K}$. The calculation of the inverse function $\nu$ has practical interest for example in the flow expansion over a dihedral supersonic applied to the external flows. The nozzle is another example for internal flows.

The purpose of calculating the value of $M_{2}$, is linked to the importance of Table 4 . Is noted from. The Table 4 the influence of gas on the downstream Mach number, will inevitably influence on thermodynamic and all geometric parameters of downstream flow $P / P_{0}, T / T_{0}, \rho / \rho_{0}, A / A^{*}$.

Figure 6 shows the error between the $\nu$ for different gases and is the air depending on $M$, where $T_{0}=2000 \mathrm{~K}$. For $\mathrm{H}_{2}$, the difference could go to $4.77 \%$ and $62.00 \%$ for $\mathrm{CH}_{4}$ when $M_{S}=5.00$. This variation depends on $M_{S}, T_{0}$ and the gas itself, considering the $P M$ function equal to zero when $M=1.00\left(T=T_{*}\right)$ from Equation (6). Then the error analysis has problem of calculation by computer (zero under zero). In this case, the obtained error is presented in Table 5.
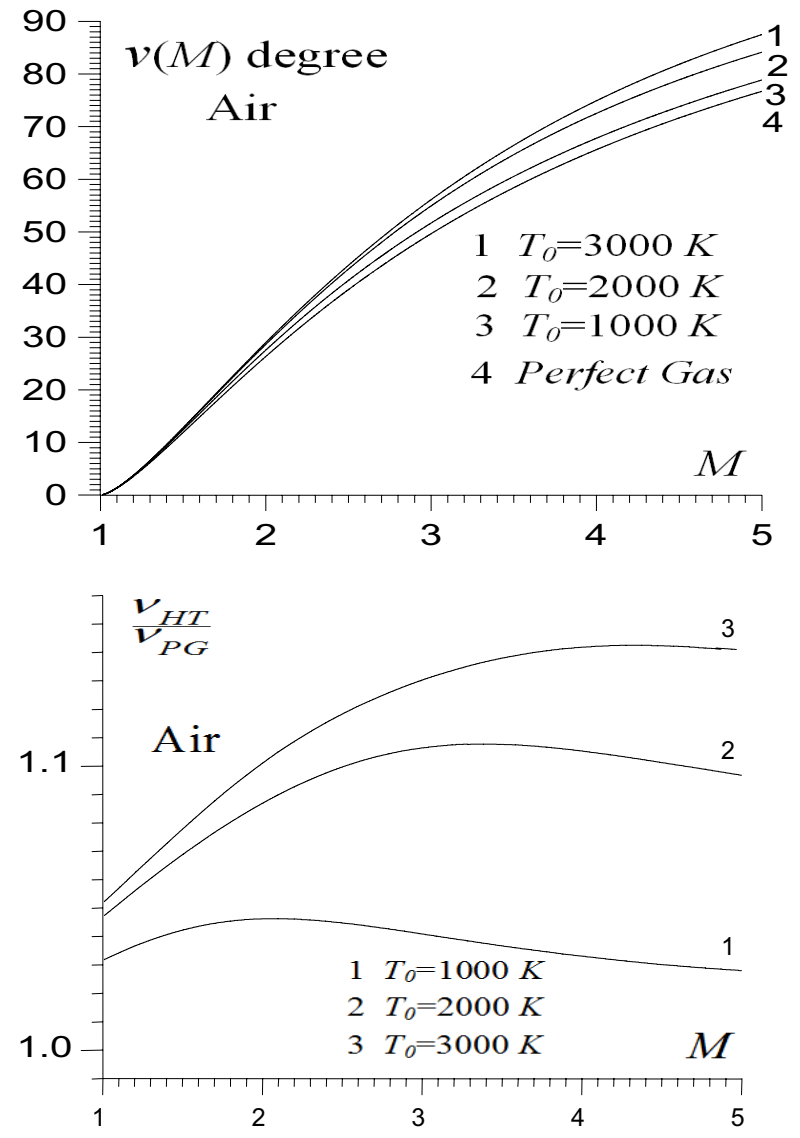

Fig. 8. Effect of caloric imperfections on the Prandtl Meyer function for $M$ for air.

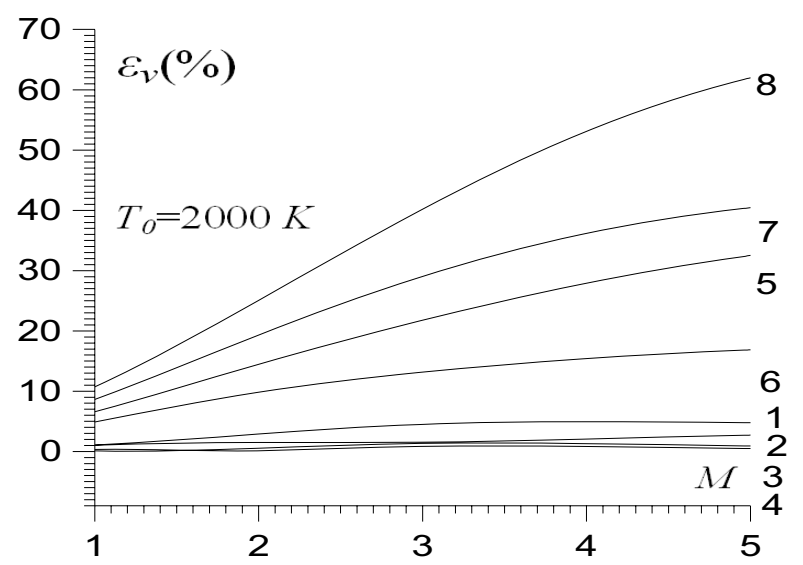

Fig. 9. Variation of error on $\nu$ for different gases with respect to the air depending on $M$.

Figure 10 shows an example of the effect of propelling gas on the shape of the supersonic nozzles kind $M L N 2 \mathrm{D}$ giving all exit Mach number $M_{\mathrm{S}}=3.00$ for $T_{0}=2000 \mathrm{~K}$. The purpose of this figure is to show the effect of gas on the initial deflection of the wall at the throat, presented by the angle $\theta^{*}$, which depends on the $P M$ value, shown in Table 6 . Note well the opening and closing of the wall at the throat according to the type of gas. For example, the 
M. Boun-jad et al.: Mechanics \& Industry 18, 219 (2017)

Table 4. Gas effect on the value of $M$ when the function $\nu$ is given for $T_{0}=2000 \mathrm{~K}$.

\begin{tabular}{cccccccc}
\hline$N$ & Gas & $\nu=10 \mathrm{deg}$ & $\nu=20 \mathrm{deg}$ & $\nu=30 \mathrm{deg}$ & $\nu=40 \mathrm{deg}$ & $\nu=50 \mathrm{deg}$ & $\nu=60 \mathrm{deg}$ \\
\hline 1 & $\mathrm{H}_{2}$ & 1.420 & 1.742 & 2.076 & 2.448 & 2.881 & 3.408 \\
2 & $\mathrm{O}_{2}$ & 1.410 & 1.718 & 2.030 & 2.369 & 2.752 & 3.199 \\
3 & $\mathrm{~N}_{2}$ & 1.414 & 1.728 & 2.051 & 2.404 & 2.809 & 3.291 \\
4 & $\mathrm{CO}$ & 1.413 & 1.726 & 2.046 & 2.397 & 2.798 & 3.275 \\
5 & $\mathrm{CO}_{2}$ & 1.386 & 1.661 & 1.926 & 2.196 & 2.477 & 2.778 \\
6 & $\mathrm{H}_{2} \mathrm{O}$ & 1.393 & 1.679 & 1.959 & 2.251 & 2.567 & 2.918 \\
7 & $\mathrm{NH}_{3}$ & 1.378 & 1.643 & 1.896 & 2.148 & 2.408 & 2.681 \\
8 & $\mathrm{CH}_{4}$ & 1.370 & 1.626 & 1.864 & 2.098 & 2.333 & 2.572 \\
9 & Air & 1.414 & 1.726 & 2.045 & 2.391 & 2.782 & 3.247 \\
\hline
\end{tabular}

Table 5. Error on $\nu$ for $M=1.00$.

\begin{tabular}{cccccc}
\hline Gas & $\varepsilon(\%)$ & Gas & $\varepsilon(\%)$ & Gas & $\varepsilon(\%)$ \\
\hline $\mathrm{H}_{2}$ & 1.061 & $\mathrm{CO}$ & 0.335 & $\mathrm{NH}_{3}$ & 0.335 \\
$\mathrm{O}_{2}$ & 1.029 & $\mathrm{CO}_{2}$ & 6.573 & $\mathrm{CH}_{4}$ & 6.573 \\
$\mathrm{~N}_{2}$ & 0.082 & $\mathrm{H}_{2} \mathrm{O}$ & 4.893 & & \\
\hline
\end{tabular}

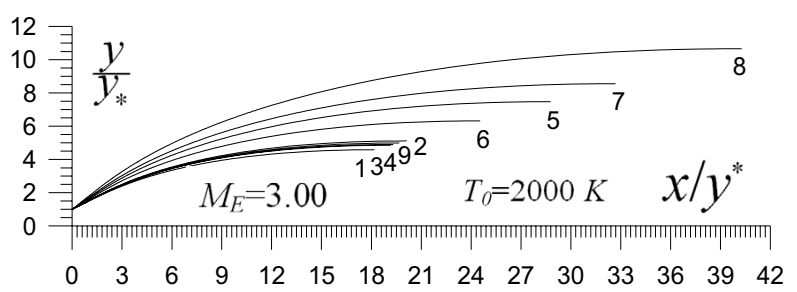

Fig. 10. Gas effect at high temperature on the shape of the $M L N 2 \mathrm{D}$ nozzle for nine selected gases.

Table 6. Design values for the nozzles of Figure 10.

\begin{tabular}{ccccccc}
\hline$N$ & Gas & $\theta^{*}(\mathrm{deg})$ & $L / y^{*}$ & $C_{\text {Mass }}$ & $C_{F}$ & $y_{E} / y_{*}$ \\
\hline 1 & $\mathrm{H}_{2}$ & 26.228 & 18.173 & 18.724 & 0.323 & 4.582 \\
2 & $\mathrm{O}_{2}$ & 27.885 & 20.134 & 20.796 & 0.357 & 5.113 \\
3 & $\mathrm{~N}_{2}$ & 27.101 & 19.175 & 19.782 & 0.341 & 4.853 \\
4 & $\mathrm{CO}$ & 27.239 & 19.326 & 19.942 & 0.344 & 4.895 \\
5 & $\mathrm{CO}_{2}$ & 33.441 & 28.783 & 29.970 & 0.482 & 7.476 \\
6 & $\mathrm{H}_{2} \mathrm{O}$ & 31.078 & 24.550 & 25.476 & 0.426 & 6.319 \\
7 & $\mathrm{NH}_{3}$ & 35.440 & 32.685 & 34.126 & 0.529 & 8.556 \\
8 & $\mathrm{CH}_{4}$ & 38.503 & 40.277 & 42.218 & 0.607 & 10.661 \\
9 & Air $[2]$ & 27.465 & 19.671 & 20.306 & 0.349 & 4.986 \\
\hline
\end{tabular}

$\mathrm{CH}_{4}$ gas gives the largest opening, while the $\mathrm{H}_{2}$ gas gives the smallest opening. This angle will necessarily affect all design parameters, such as Table 6 shows it. The results for aerospace supersonic nozzles applied to missiles and supersonic aircraft are recommended for use for example the $\mathrm{H}_{2}$ gas, $\mathrm{N}_{2}$ and $\mathrm{CO}$ instead of air. For example, $\mathrm{CH}_{4}$ and $\mathrm{NH}_{3}$ gas are not recommended.

In Figures 4, 5 and 10, curves 1, 3, 4, 9 and 2 are quite close to each other, as the calorific value of the gas $\mathrm{H}_{2}$, $\mathrm{N}_{2}, \mathrm{CO}, \mathrm{O}_{2}$ and air is the same order of greatness course with a difference.

Figures 11-13 show the effect of the stagnation temperature $T_{0}$, respectively for $\mathrm{H}_{2}$ gas, $\mathrm{O}_{2}, \mathrm{~N}_{2}, \mathrm{CO}, \mathrm{CO}_{2}$, $\mathrm{H}_{2} \mathrm{O}, \mathrm{NH}_{3}, \mathrm{CH}_{4}$ and air on the design of the supersonic nozzle type $M L N 2 \mathrm{D}$, giving a uniform flow and parallel to the exit section with $M_{E}=3.00$, including the

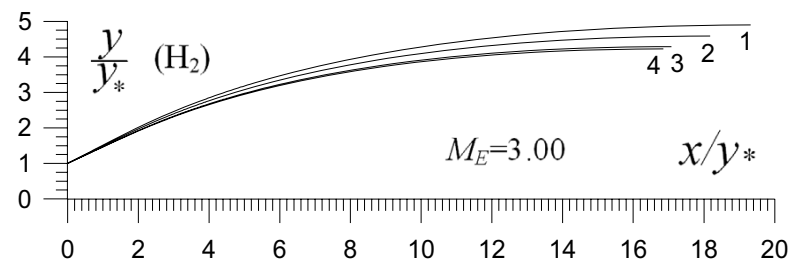

Curve 1. $T_{0}=3000 \mathrm{~K}$. Curve 2. $T_{0}=2000 \mathrm{~K}$.

Curve 3. $T_{0}=1000 \mathrm{~K}$. Curve 4. Perfect Gas model

Fig. 11. Effect of $T_{0}$ on the shape of the $2 \mathrm{D} M L N$ nozzle for $\mathrm{H}_{2}$ gas.

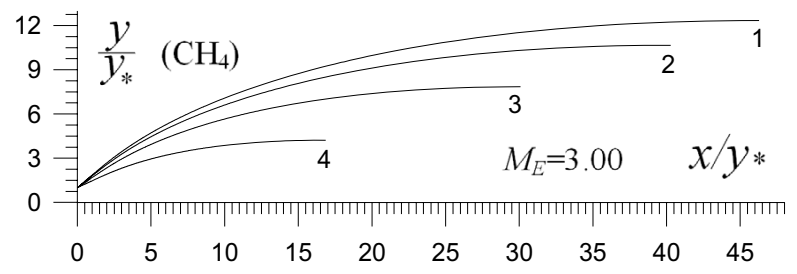

Curve 1. $T_{0}=3000 \mathrm{~K}$. Curve 2. $T_{0}=2000 \mathrm{~K}$.

Curve 3. $T_{0}=1000 \mathrm{~K}$. Curve 4. Perfect Gas model

Fig. 12. Effect of $T_{0}$ on the shape of the $2 \mathrm{D} M L N$ nozzle for $\mathrm{CH}_{4}$ gas.

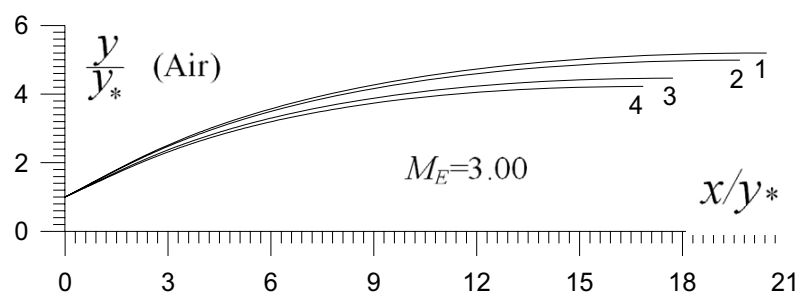

Curve 1. $T_{0}=3000 \mathrm{~K}$. Curve 2. $T_{0}=2000 \mathrm{~K}$.

Curve 3. $T_{0}=1000 \mathrm{~K}$. Curve 4. Perfect Gas model

Fig. 13. Effect of $T_{0}$ on the shape of the $2 \mathrm{D} M L N$ nozzle for air.

case of the ideal gas for constant $\gamma$. The application is for $T_{0}=1000 \mathrm{~K}, 2000 \mathrm{~K}$ and $3000 \mathrm{~K}$. The results for constant $\gamma$ (curve 4) on Figures 11-13 can be compared with the results of references $[9,10]$.

The design results of the nozzles of these figures are presented respectively in Tables 7-9. For air (Fig. 13 and Tab. 9), the results can be found in reference [2]. 
Table 7. Design values for the nozzles of Figure 11.

\begin{tabular}{cccccc}
\hline$T_{0}(\mathrm{~K})$ & $\theta^{*}(\mathrm{deg})$ & $L / y^{*}$ & $C_{\text {Mass }}$ & $C_{F}$ & $y_{E} / y_{*}$ \\
\hline 1000 & 25.1420 & 17.0834 & 17.5724 & 0.3037 & 4.2859 \\
2000 & 26.2289 & 18.1739 & 18.7247 & 0.3239 & 4.5829 \\
3000 & 27.2642 & 19.3177 & 19.9342 & 0.3441 & 4.8941 \\
Perfect & 24.8258 & 16.8522 & 17.3268 & 0.2989 & 4.2200 \\
\hline
\end{tabular}

Table 8. Design values for the nozzles of Figure 12.

\begin{tabular}{cccccc}
\hline$T_{0}(\mathrm{~K})$ & $\theta^{*}(\mathrm{deg})$ & $L / y^{*}$ & $C_{\text {Mass }}$ & $C_{F}$ & $y_{E} / y_{*}$ \\
\hline 1000 & 34.2401 & 30.0875 & 31.3622 & 0.4986 & 7.8421 \\
2000 & 38.5030 & 40.2773 & 42.2181 & 0.6075 & 10.6612 \\
3000 & 40.4941 & 46.2765 & 48.6236 & 0.6608 & 12.3329 \\
Perfect & 24.8258 & 16.8522 & 17.3268 & 0.2989 & 4.2200 \\
\hline
\end{tabular}

Table 9. Design values for the nozzles of Figure 13.

\begin{tabular}{cccccc}
\hline$T_{0}(\mathrm{~K})$ & $\theta^{*}(\mathrm{deg})$ & $L / y^{*}$ & $C_{\text {Mass }}$ & $C_{F}$ & $y_{E} / y_{*}$ \\
\hline 1000 & 25.8410 & 17.7220 & 18.2482 & 0.3161 & 4.4620 \\
2000 & 27.4658 & 19.6718 & 20.3066 & 0.3490 & 4.9861 \\
3000 & 28.0588 & 20.4559 & 21.1349 & 0.3626 & 5.1973 \\
Perfect & 24.8258 & 16.8522 & 17.3268 & 0.2989 & 4.2200 \\
\hline
\end{tabular}

It is clearly noticed the effect of $T_{0}$ and gas on the shape of the nozzle. So, the most temperature $T_{0}$ is higher, it will have a broader form of the nozzle to keep the uniform and parallel flow to the exit section. Therefore, the temperature $T_{0}$ affects the thrust coefficient and generally the performances of the nozzle. For air (Fig. 13), the results can be compared with the results of references $[3,13,14]$.

For a small mass of the nozzle we must choose a value of $T_{0}$ as small as possible, which is the case for some aerospace applications. But if applications do not allow, in this case we must design the suitable shape to the temperature $T_{0}$. For the selection of gas, it is noted that the $\mathrm{CH}_{4}$ gas, $\mathrm{NH}_{3}, \mathrm{CO}_{2}, \mathrm{H}_{2} \mathrm{O}$ not agree for use as aerospace propulsion gases. The best choice is the $\mathrm{H}_{2}$ (Fig. 11), air (Fig. 13) and $\mathrm{N}_{2}$. The same comments are valid for any exit Mach number $M_{E}$.

\section{Conclusion}

This work allows us to study the effect of using gas of propulsion at high temperature on the $P M$ function and makes applications for designing the supersonic 2D $M L N$ nozzle. We can draw the following conclusions:

- The developed numerical program can study any gas found in the literature. In this case, we must add the function $C_{P}(T)$ and the gas constant $R$ even calculation the enthalpy $H(T)$.

- For the calculation of the supersonic flow parameters as function of stagnation temperature, Supersonic Mach number and the used gas are necessary.

- $C_{P}(T), R$ and $\gamma(T)$ characterize the calorific value of the gas, and necessarily influence the $P M$ function.

- The presented relation is valid for any interpolation form chosen for the function $C_{P}(T)$ of the selected gases. The essential one is that the interpolation gives an acceptable small error.

- The stagnation temperature and the Mach number also influence the $P M$ function.

- The most ratio $\gamma$ of the gas is small, the $P M$ function becomes larger. Among the selected gas, it is the case for $\mathrm{CH}_{4}$.

- In addition to $T_{0}$ and $M_{S}$ affecting the opening of the nozzle to the throat (which affects the size and shape of the nozzle), the gas itself also influences.

- The propellant gas affects all thermodynamic and design parameters.

In the same line of research, we can use the present work to study the effect of gas propulsion at high temperature on the design of various forms of supersonic nozzles as $M L N$, plug nozzle, end nozzle, bell shaped nozzle, dual nozzle for $2 \mathrm{D}$, and $3 \mathrm{D}$ and axisymmetric geometries by the method of characteristics.

One can even consider the propulsion gas effect on the determination of the drag force caused by friction and in particular the drag coefficient, the thickness of displacement, momentum and energy thickness of the boundary layer developed through the wall of the nozzle.

Acknowledgements. The authors acknowledge Khaoula, AbdelGhani Amine, Ritadj and Assil Zebbiche and Mouza Ouahiba for granting time to prepare this manuscript.

\section{References}

[1] C.R. Peterson, P.G. Hill, Mechanics and Thermodynamics of Propulsion, Addition-Wesley Publishing Company Inc., New York, USA, 1965

[2] G.P. Sutton, O. Biblarz, Rocket Propulsion Elements, $8^{\mathrm{e}}$ édition, John Wiley and Sons, 2010

[3] T. Zebbiche, Z. Youbi, Supersonic two-dimensional minimum length nozzle design at high temperature. Application for air, Chinese J. Aeronautics 20 (2007) 29-39

[4] T. Zebbiche, Stagnation temperature effect on the supersonic axisymmetric minimum length nozzle design with application for air, Adv. Space Res. 48 (2011) 1656-1675

[5] H. Gerald, L. Hans, V.N. Thong, E.D. Gennady, Advanced Rocket Nozzle, J. Propuls. Power 14 (1998) $316-326$

[6] G. Hagemann, H. Immich, M. Terhardt, Flow Phenomena in advanced rocket nozzles-The plug nozzle, AIAA-19983522, 34th AIAA/ASME/SAE/ ASEE Joint Propulsion Conference and Exhibit, Cleveland, OH, July 13-15, 1998

[7] G. Hagemann, H. Immich, T. Van Nguyen, G.E. Dumnov, Advanced Rocket Nozzles, J. Propuls. Power 14 (1998) 620-634

[8] G. Hagemann, H. Immich, A. Preuss, Advanced Nozzle Concepts for Future Rocket Engine Applications, 4th International Conference on Launcher Technology, Liege, Belgium, December 3-6, 2002

[9] F.J. Malina, Characteristics of the rocket motor based on the theory of perfect gases, J. Franklin Inst. 230 (1940) $433-450$ 
[10] C.B. Johnson, L.R. Boney, A Method for Calculating a Real-Gas Two-Dimensional Nozzle Contour Including the Effects of Gamma, NASA TM X-3243, Sep. 1975

[11] T. Zebbiche, Z. Youbi, Supersonic Flow Parameters at High Temperature. Application for Air in nozzles, German Aerospace Congress 2005, DGLR-2005-0256, 26-29 Sep. 2005, Friendrichshafen, Germany

[12] T. Zebbiche, Z. Youbi, Effect of stagnation temperature on the supersonic flow parameters with application for air in nozzles, Aeronautical J. 111 (2007) 31-40

[13] T. Zebbiche, Z. Youbi, Supersonic Two-Dimernsional Minimum Length Nozzle Design at High Temperature. Application for Air, AIAA-2006-4599, 42nd AIAA/ASME/SAE/ASEE Joint Propulsion Conference \& Exhibit, Sacramento, California, July 09-12, 2006

[14] T. Zebbiche, Z. Youbi, Design of Two-Dimensional Supersonic Minimum Length Nozzle at High Temperature. Application for Air, German Aerospace Congress, Friendrichshafen, Germany, 26-29 September 2005, DGLR 2005-257

[15] T. Zebbiche, Z. Youbi, Supersonic plug nozzle design at high temperature. Application for air, Chinese J. Aeronautics 20 (2007) 15-28

[16] T. Zebbiche, Z. Youbi, Supersonic Plug Nozzle Design at High Temperature. Application for Air, AIAA-2006-0592, 44th Aerospace Sciences Meeting and Exhibit, 9-12 Jan. 2006, Reno Nevada, Reno Hilton, USA

[17] O. Abada, T. Zebbiche, A. Abdallah El-Hirtsi, Threedimensional supersonic minimum length nozzle design at high temperature for arbitrary exit cross section, Arab. J. Sci. Eng. 39 (2014) 8233-8245

[18] T. Zebbiche, Stagnation temperature effect on the Prandtl Meyer function, AIAA J. 45 (2007) 952-954

[19] T. Zebbiche, M. Boun-jad, Numerical quadrature for the Prandtl-Meyer function at high temperature with application for air, Thermophys. Aeromech. 19 (2012) $381-384$
[20] Haynes W.M., CRC Handbook of Chemistry and Physics, 93th edition, CRC Press/Taylor and Francis, Boca Raton, 2012

[21] G.J. Van Wylen, Fundamentals of classical thermodynamics, John Wiley and Sons, Inc. 1973

[22] L.G. Newton, M. Randall, Thermodynamics, 2nd edition, McGraw-Hill Book Company, New York, 1961

[23] B.J. McBride, S. Gordon, M.A. Reno, Coefficients for Calculating Thermodynamic and Transport Properties of Individual Species, NASA TM 4513, 1993

[24] J.C. Hunsaker, Equations, Tables and Charts for Compressible Flow, NACA TR 1135, 1953

[25] A. Burcat, Thermochemical Data for Combustion Calculations, Combustion Chemistry, edited by W.C. Gardiner, Jr., Springer-Verlag, New York, 1984, Chap. 8

[26] A. Burcat, B. McBride, Ideal Gas Thermodynamic Data for Compounds Used in Combustion and Air-Pollution, TAE 675, Technion Israel Institute of Technology, Haifa, Israel, 1992

[27] J. Chao, R.C. Wilhoit, B.J. Zwolinski, Ideal Gas Thermodynamic Properties of Ethane and Propane, J. Phys. Chem. Ref. Data 2 (1973) 427-437

[28] R. Comolet, Mécanique Expérimentale des Fluides. Statique et Dynamique des Fluides Non Visqueux, 3rd edition, Masson, 1979, Tome 1

[29] H. Shapiro, M. Moran, Fundamentals of Engineering Thermodynamics, John Wiley and Sons Ltd, England, 2006

[30] A. Raltson, A. Rabinowitz, A First Course in Numerical Analysis, McGraw Hill Book Company, 1985

[31] B. Démidovitch, I. Maron, Éléments de calcul numérique, Editions MIR, Moscow, Russia, 1987

[32] J.D.JR. Anderson, Modern Compressible Flow With Historical Perspective, 2nd edition, McGraw-Hill Book Company, New York, USA, 1982 